\title{
A method for preparation and cleaning of uniformly sized arsenopyrite particles
}

\author{
Hariprasad Parthasarathy', John P Baltrus ${ }^{2}$, David A Dzombak ${ }^{1}$ and Athanasios K Karamalidis ${ }^{{ }^{*}}$
}

\begin{abstract}
Background: The oxidative dissolution of sulfide minerals, such as arsenopyrite (FeAsS), is of critical importance in many geochemical systems. A comprehensive understanding of their dissolution rates entails careful preparation of the mineral surface. Measurements of dissolution rates of arsenic from arsenopyrite are dependent on the size and degree of oxidation of its particles, among other factors. In this work, a method was developed for preparation and cleaning of arsenopyrite particles with size range of 150-250 $\mu \mathrm{m}$. Four different cleaning methods were evaluated for effectiveness based on the removal of oxidized species of iron (Fe), arsenic (As) and sulfur (S) from the surface. The percentage oxidation of the surface was determined using X-ray photoelectron spectroscopy (XPS), and surface stoichiometry was measured using scanning electron microscopy - energy dispersive X-ray spectroscopy (SEM-EDS).

Results: Results indicate that sonicating the arsenopyrite particles and then cleaning them with $12 \mathrm{~N} \mathrm{HCl}$ followed by $50 \%$ ethanol, and drying in nitrogen was the most effective method. This method was successful in greatly reducing the oxide species of Fe while completely removing oxides of $\mathrm{As}$ and $\mathrm{S}$ from the arsenopyrite surface.

Conclusions: Although sonication and acid cleaning have been widely used for mineral preparation, the method described in this study can significantly reduce grain size heterogeneity as well as surface oxidation, which enables greater control in surface and dissolution experiments.
\end{abstract}

Keywords: Arsenopyrite, XPS, Mineral preparation, Surface cleaning, Oxidation

\section{Background}

Arsenopyrite (FeAsS (s)) is the most common arsenic (As) bearing pure phase mineral in the earth's crust. It is present in a variety of deposits such as hydrothermal, and magmatic systems and is an important reservoir of arsenic in the subsurface. Due to its common association with gold, it is often discarded as solid waste after gold extraction. The oxidation of arsenopyrite can release As into the environment which has potential environmental and health impacts [1].

A number of studies [2-5] have been conducted that investigate the kinetics of arsenopyrite dissolution with oxidants such as dissolved oxygen and iron, but there is significant variation in reported rates. One of the possible sources of this variation is the lack of a consistent mineral preparation procedure. Differences in mineral preparation can significantly affect grain size distribution

\footnotetext{
*Correspondence: akaramal@andrew.cmu.edu

1 Department of Civil and Environmental Engineering, Carnegie Mellon University, Pittsburgh, PA 15213, USA

Full list of author information is available at the end of the article
}

as well as affect the extent of oxidation on the surface prior to conducting dissolution studies.

Previous research [3] indicates that grain sizes can exert significant control over oxidation and dissolution rates. McKibben et al. [3] determined that 150-250 $\mu \mathrm{m}$ was the most convenient grain size for arsenopyrite dissolution. Arsenopyrite is typically prepared by homogenous grinding of the sample in a mortar and pestle, and then dry sieved to obtain required size fractions. Fine particles have high specific surface areas and their presence in these fractions can cause exaggerated dissolution rates [6], as well as affect reproducibility of dissolution experiments. Typically, sonication of crushed mineral in ethanol or acetone has been used to remove fines from the surface of sulfide minerals $[3,7,8]$.

Dissolution studies can be further complicated by the presence of oxidized species on the mineral surface, which can lead to erroneous initial rates [2]. Since the dissolution of arsenopyrite is oxidative in nature, oxidized species on the surface could drive subsequent dissolution of arsenopyrite. Acid cleaning has been used extensively in the

\section{Chemistry Central}


literature as a method of cleaning sulfide minerals such as pyrite and arsenopyrite, but relies on indirect methods such as initial sulfate release to determine the extent of surface oxidation. Moses et al. [9] reported the use of a combination of boiling $6 \mathrm{~N} \mathrm{HCl}$ and acetone for surface cleaning of pyrite. The extent of oxidation was determined by monitoring the immediate release of $\mathrm{SO}_{4}^{2-}$ into solution. In the case of arsenopyrite, McKibben at al. [3] reported the use of $1.8 \mathrm{~N} \mathrm{HNO}_{3}$ for cleaning, while other groups $[2,4]$ did not report methods for surface oxide removal. Oxidized iron and arsenic were observed to be removed from the surface of arsenopyrite when it was immersed in an air-saturated acetic acid solution [10]. However, studies on the relative rates of elemental oxidation of arsenopyrite upon exposure to air have shown that As and Fe oxidize at rates faster than $S[11,12]$, suggesting that measurement of immediate release of sulfate into solution might not accurately reflect the extent of surface oxidation. As a result, there exists a need for direct evaluation of acid cleaning as a viable method for surface oxide removal on arsenopyrite prior to dissolution experiments. Typically, X-ray photoelectron spectroscopy (XPS) has been used to study surface oxidation on many minerals, but studies on arsenopyrite have been limited to vacuum fractured pristine surfaces and surfaces exposed to oxidants.

The objective of this study was to develop a reproducible and effective procedure to generate arsenopyrite particles of a uniform size fraction, free of surface oxides. The specific objectives were to (i) obtain arsenopyrite particles of the size fraction $150-250 \mu \mathrm{m}$ by removing fines adhering to the surface, and (ii) clean the surface of crushed particles to remove oxide species of Fe, As and S, without altering the stoichiometry of the mineral. The effectiveness of $\mathrm{HCl}$ and acetic acid for cleaning the surface of arsenopyrite was evaluated, based on their reported use for this purpose in the literature. The resulting method developed for cleaning the arsenopyrite surface was verified through XPS, particle size distribution analysis, and scanning electron microscopy - energy dispersive X-ray spectroscopy (SEM-EDS).

\section{Results and discussion}

\section{Particle size analysis}

The results of the particle size distribution are shown in Figure 1 . The particles were normally distributed with a mean diameter of $208.9 \mu \mathrm{m}$ and a standard deviation of $1.764 \mu \mathrm{m}$, and the median was $219.2 \mu \mathrm{m}$. This suggests that while the distribution was not entirely symmetric, a large fraction of particles was within the size range of 150-250 $\mu \mathrm{m}$.

\section{XPS}

\section{Drying}

The effects of two different drying protocols on the extent of arsenopyrite surface oxidation can be seen by examining the results of curve fitting the three elemental regions: As 3d, Fe 2 $\mathrm{p}_{3 / 2}$, and S $2 \mathrm{p}$ in Table 1.

Representative curve-fitted XPS spectra for a sample prior to treatment are shown in Figure 2 (A-C). Excellent fits of the overall As $3 \mathrm{~d}$ spectra (Figure $2 \mathrm{~A}$ ) could be obtained using a minimum of three peak doublets $\left(3 \mathrm{~d}_{5 / 2}\right.$ and $3 \mathrm{~d}_{3 / 2}$ separated by $0.64 \mathrm{eV}$ ) corresponding to two types of oxidized arsenic species along with unoxidized arsenic. The oxidized species with $3 \mathrm{~d}_{5 / 2}$ binding energy $45.1 \mathrm{eV}$ is most likely $\mathrm{As}^{5+}$, while the smaller doublet with a $3 \mathrm{~d}_{5 / 2}$ binding energy of $43.9 \mathrm{eV}$ is between the values typically

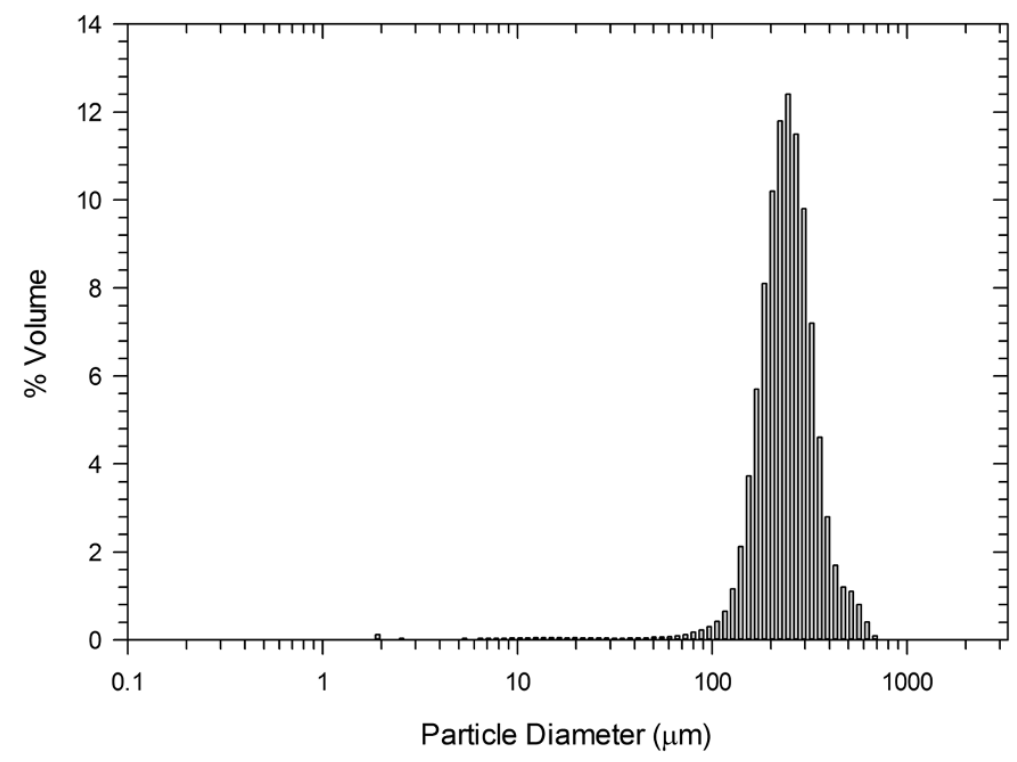

Figure 1 Particle size distribution of prepared arsenopyrite particles expressed as volume \%. 
Table 1 The effect of drying method on surface oxidation of arsenopyrite

\begin{tabular}{llll}
\hline Drying method & \multicolumn{3}{l}{ \% Oxidation on the surface } \\
\cline { 2 - 4 } & $\mathrm{Fe}$ & As & S \\
\hline In air, $105^{\circ} \mathrm{C}$ & 93.9 & 92.0 & 63.7 \\
In air, $25^{\circ} \mathrm{C}$ & 43.8 & 42.9 & 11.9 \\
\hline
\end{tabular}

reported for $\mathrm{As}^{1+}$ and $\mathrm{As}^{3+}$ [1]. The Fe $2 \mathrm{p}_{3 / 2}$ spectra were also fitted with 2 peaks, corresponding to oxidized and unoxidized Fe (Figure 2B). No attempt was made to resolve the broad peak assigned to oxidized Fe into components that could be attributed to individual oxidation states since our only concern was the relative amounts of oxidized and unoxidized Fe. The S $2 p$ spectra were resolved into three sets of doublets (Figure $2 \mathrm{C}$ ) corresponding to the unoxidized sulfide ( $\left.2 \mathrm{p}_{3 / 2}=162.0 \mathrm{eV}\right)$, a metal-deficient sulfide (S $\left.2 \mathrm{p}_{3 / 2}=163.2-163.7 \mathrm{eV}\right)$, and oxidized sulfur in the form of sulfate $\left(\mathrm{S} 2 \mathrm{p}_{3 / 2}=167.7 \mathrm{eV}\right)$.

The reported percentages of oxidation were calculated based solely on the fraction of each element that is bound to oxygen. While the extents of oxidation measured from the Fe $2 \mathrm{p}_{3 / 2}$ and As $3 \mathrm{~d}$ spectra for a given sample agreed within experimental error, the degree of sulfur oxidized to sulfate measured from the $S 2 p$ spectra for the same sample was much less. This has been commonly attributed to the formation of a metal-deficient sulfide species in other studies of the oxidation of pyrite and arsenopyrite surfaces $[10,13,14]$. Further, sulfur on the arsenopyrite surface, oxidizes at a rate much lower than iron and arsenic $[11,15]$, thereby resulting in a lower extent of sulfur oxidation on the surface.

The results in Table 1 clearly indicate that the drying procedure at room temperature is preferable to drying at $105^{\circ} \mathrm{C}$ as it limits the extent of surface oxidation. Thus, this procedure was implemented for drying the samples prior to applying various treatments to remove surface oxidation.

\section{Removal of surface oxide species}

The percentages of oxidation of each element determined from peak fitting the XPS spectra of the arsenopyrite samples after the application of various cleaning methods being tested to remove oxidized surface species are shown in Figure 3. The corresponding XPS spectra for the sample cleaned with $\mathrm{HCl}$ are shown in Figure 2D-2F.

The results indicate that treatment with the strong acid $\mathrm{HCl}$ was more effective in removing surface oxidation than treatment with the weak acid, acetic acid. A higher concentration of $\mathrm{HCl}$ was more effective in removing the last traces of surface oxidation over the given treatment time. Within the acetic acid treatments, increasing the treatment time resulted in increased removal of oxidized surface species, but even a treatment time of 20 minutes was insufficient for complete removal of oxidized species.

Only $12 \mathrm{~N} \mathrm{HCl}$ removed all oxidized species of sulfur and arsenic over the given treatment time. However, all four methods failed to remove oxidized iron completely, with $12 \mathrm{~N} \mathrm{HCl}$ being the most effective. For the case of $12 \mathrm{~N} \mathrm{HCl}$, fitting of the $\mathrm{Fe} 2 \mathrm{p}_{3 / 2}$ spectra still indicated some residual surface oxidation. The presence of oxidized iron species has also been observed on vacuum fractured surfaces of arsenopyrite by Nesbitt et al. [11], who reported that $\sim 17 \%$ of the $\mathrm{Fe}$ on the surface could be attributed to $\mathrm{Fe}$ (III)-(As-S) species. Moreover, the overall higher surface sensitivity of the XPS measurement to the Fe $2 p$ level compared to As 3d and S 2p and/or some small amount of preferential reoxidation of Fe during the sample's exposure to air during its transfer to the XPS instrument could have also resulted in the detection of oxidized iron species, even after cleaning the surface. Comparing the $\mathrm{S} 2 \mathrm{p}$ spectra before and after the $\mathrm{HCl}$ treatment, one can see that while all the sulfur oxidized to sulfate has been completely removed by the treatment, the relative percent of metal-deficient polysulfide increased from $5 \%$ to $17 \%$ of the non oxygenbound sulfur species. Although metal deficient polysulfide species have been reported in vacuum fractured arsenopyrite [1], oxidation of samples during procurement and grinding could have resulted in the formation of polysulfides on the surface $[10,13,14]$.

While the $12 \mathrm{~N} \mathrm{HCl}$ cleaning method can be used for other sulfide minerals, using $12 \mathrm{~N} \mathrm{HCl}$ might not be appropriate for acid volatile sulfides (AVS) such as galena $(\mathrm{PbS})$, which dissolve in concentrated $\mathrm{HCl}$ [16].

\section{SEM-EDS}

SEM images of freshly prepared arsenopyrite particles, cleaned with $12 \mathrm{~N} \mathrm{HCl}$ and $50 \%$ ethanol are shown in Figure 4 . The ground mineral particles are uniformly sized and the surfaces do not show the presence of any fine particles (Figure 4A). The arsenopyrite particles were analyzed for iron, arsenic and sulfur using EDS (Figure 4B) and the measured weight percentages were converted to stoichiometric quantities. The prepared arsenopyrite sample was divided into ten batches and five measurements (Figure 4B) were made per batch. The average stoichiometry was found to be $\mathrm{Fe}_{1.04 \pm 0.08} \mathrm{As}_{0.96 \pm 0.05} \mathrm{~S}_{1.03 \pm 0.04}$. Considering that sulfur on arsenopyrite oxidizes at a rate lower than Fe and As $[11,15]$, the surface is expected to be sulfur enriched after cleaning with $\mathrm{HCl}$. While XPS measurements indicated some enrichment, the average mineral stoichiometry measured by SEM-EDS was close to the theoretical stoichiometry of FeAsS. Surface sulfur enhancement measured through XPS can be included in dissolution rate calculations while conducting dissolution experiments 
Figure 2 XPS spectra depicting speciation of $\mathrm{As}, \mathrm{Fe}$, and $\mathrm{S}$ on arsenopyrite. Representative curve fitted XPS spectra for (A) arsenic As 3d, (B) iron- Fe 2p, and (C) sulfur - S 2p, for a sample of arsenopyrite prior to any treatments to remove surface oxidation. (D) Arsenic- As 3d, (E) iron- Fe $2 p$, and (F) sulfur- S $2 p$, for a sample of arsenopyrite treated with $12 \mathrm{~N} \mathrm{HCl}$ to remove surface oxides.

to ensure accurate measurement of rates of Fe, As, and $S$ release.

Further, SEM images of arsenopyrite particles before (Figure 4C) and after treatment with $12 \mathrm{~N} \mathrm{HCl}$ (Figure 4D) did not reveal any significant morphological changes on the surface suggesting minimal change in the specific surface area of the mineral particles due to acid treatment. A comparison between the images depicts an absence of pitting or etching from acid treatment.

\section{Experimental}

\section{Mineral preparation and reagents}

Arsenopyrite from Hunan province in China was obtained from Wards Science Inc. (Rochester, NY) in $10 \mathrm{~g}$ batches. Each batch was ground to powder using a porcelain mortar and pestle. The mortar and pestle were soaked with $10 \% \mathrm{HNO}_{3}(\mathrm{w} / \mathrm{v})$ overnight prior to being used for the first time. The powdered arsenopyrite was then dry sieved using $250 \mu \mathrm{m}$ and $150 \mu \mathrm{m}$ nylon sieves, which were also soaked in $10 \% \mathrm{HNO}_{3}(\mathrm{w} / \mathrm{v})$ overnight. The fraction of particles between 150-250 $\mu \mathrm{m}$ was collected and transferred into a plastic tube. From every $10 \mathrm{~g}$ batch of mineral, $5 \mathrm{~g}$ in the 150-250 $\mu \mathrm{m}$ fraction was obtained in this manner.

ACS reagent grade acids ( $\mathrm{HCl}$, acetic acid) were used in all cleaning experiments. All aqueous solutions were prepared using ultra-pure water (18.2 MOhm.cm, Barnstead Nanopure purifying system). Laboratory grade nitrogen (99.9\% purity) was used in all experiments for mineral drying.

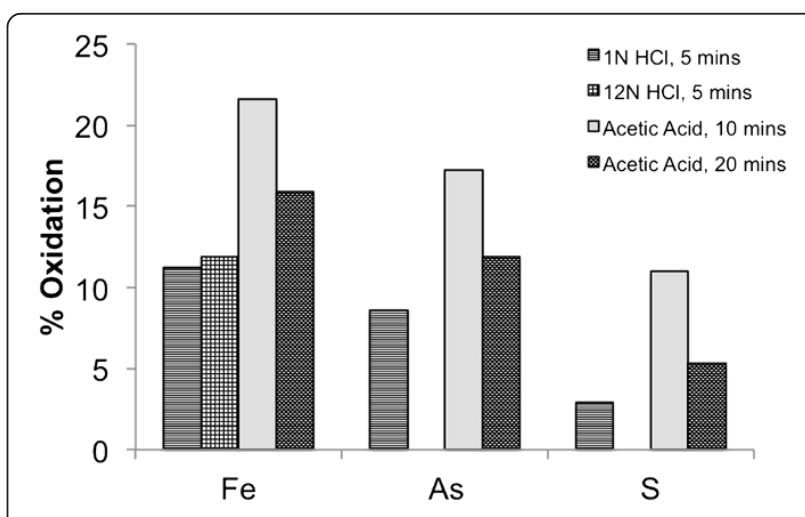

Figure 3 Percentages of $\mathrm{Fe}, \mathrm{As}$, and $\mathrm{S}$ oxidation determined from XPS spectra of arsenopyrite after various cleaning procedures. 


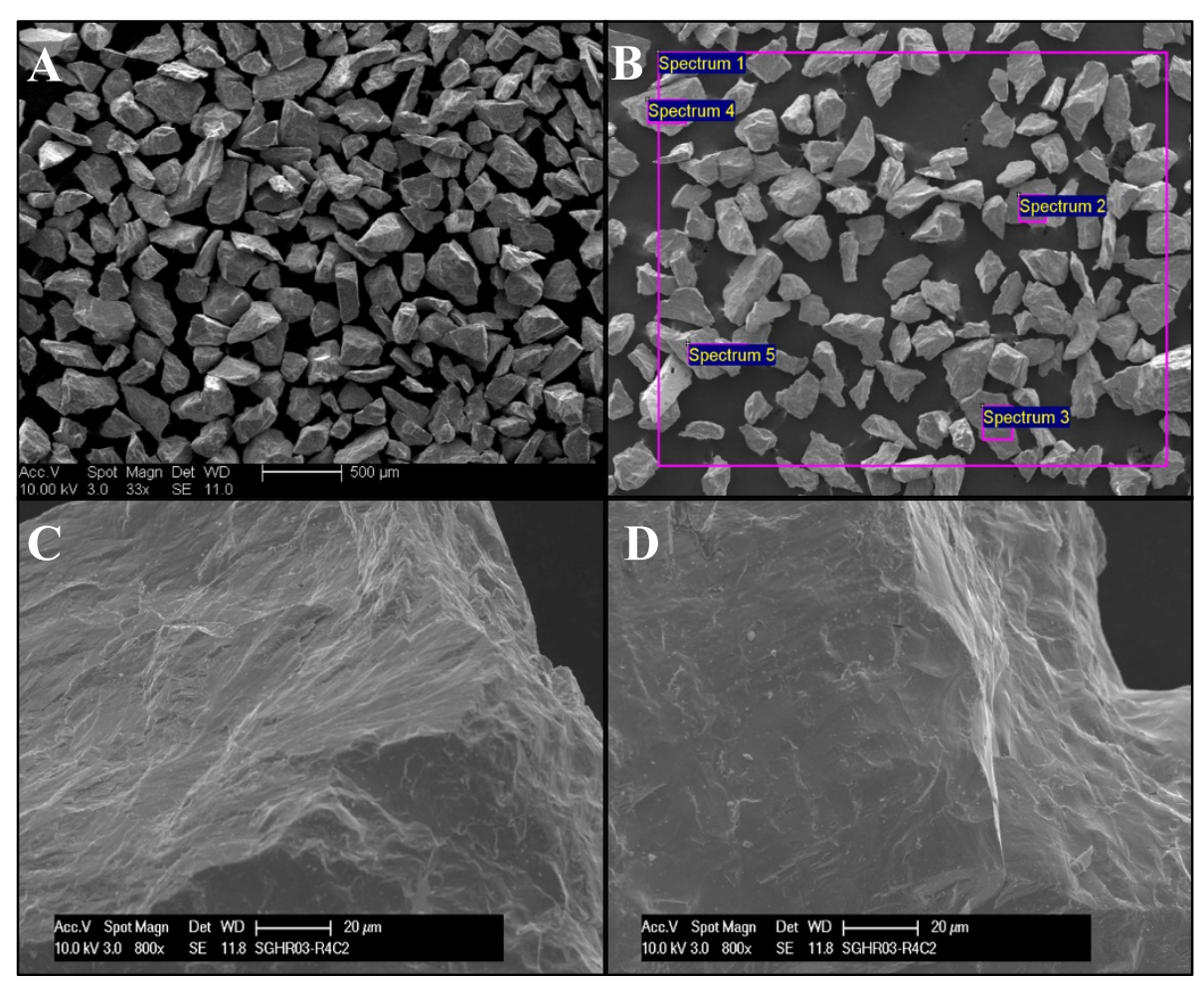

Figure 4 SEM analysis of arsenopyrite particles. (A) Secondary electron image of clean size segregated arsenopyrite particles (B) Sample surface composition measurements of arsenopyrite using SEM-EDS. Comparison of SEM images between (C) arsenopyrite surface prior to acid treatment and (D) arsenopyrite surface after cleaning with $12 \mathrm{~N} \mathrm{HCl}$ reveals no significant morphological changes to the surface of the mineral.

\section{Surface cleaning}

Surface cleaning of arsenopyrite consisted of two steps:

1. Removal of fine particles adhered to the surface: particles significantly smaller than the sieved range can be electrostatically bound to the surface of larger particles. Such fines could result in exaggerated measurement of dissolution rates and hence need to be removed.

To remove fines, the particles were sonicated with $50 \%(\mathrm{v} / \mathrm{v})$ ethanol for 3 minutes using a Branson 5200 sonicator (Branson Inc., Connecticut, USA). Upon sonication, the ethanol phase turned black in color indicating suspended fine particles, and was subsequently decanted. This process was repeated three times and the particles were transferred to a petri dish and dried. Since drying the particles could affect the extent of surface oxidation, two different methods of drying were evaluated: a) drying the particles in air at $105^{\circ} \mathrm{C}$ for 15 minutes and b) drying the particles in air for 1 hour at room temperature $\left(25^{\circ} \mathrm{C}\right)$. The dried arsenopyrite particles were then subjected to XPS analysis and a method for drying was chosen based on the extent of surface oxidation. Limiting the extent of initial surface oxidation enables easier removal of oxidized layers from the surface.
2. Removal of oxide layers - limited surface oxidation can occur during crushing, sieving, and drying of arsenopyrite. This can impact initial dissolution rate determination, as the rate of oxide phase dissolution can be significantly different from that of arsenopyrite. Further, arsenopyrite dissolution being oxidative in nature could be affected by dissolved oxidized species.

Removal of oxides to the largest possible extent aids in accurate initial rate measurements. Oxides on the surface were removed by washing the arsenopyrite particles with acid.

Four methods for surface oxide removal were evaluated to identify an effective protocol for surface cleaning. These methods are shown in Table 2. As indicated there, the methods were similar except for the acid employed in the first rinse step, which involved either $\mathrm{HCl}(1 \mathrm{~N}$ or $12 \mathrm{~N})$ or $50 \% \mathrm{v} / \mathrm{v}$ acetic acid.

After cleaning the particles, samples intended for XPS analysis were placed in glass vials, flushed with $\mathrm{N}_{2}$, crimped, and transported in vacuum containers capable of maintaining vacuum of 14.7" $\mathrm{Hg}$ for over 24h, (DesiVac $700 \mathrm{~mL}$ containers, Cole palmer, USA). All samples were analyzed the same day that the cleaning method was applied. 
Table 2 Methods for cleaning surface oxides on arsenopyrite particles

\begin{tabular}{|c|c|c|c|c|c|c|c|}
\hline Method & $\begin{array}{l}\text { Particle } \\
\text { size }\end{array}$ & $1^{\text {st }}$ Rinse & $2^{\text {nd }}$ Rinse & $3^{\text {rd }}$ Rinse & $\begin{array}{l}\text { Drying } \\
\text { environment }\end{array}$ & $\begin{array}{l}\text { Drying } \\
\text { duration }\end{array}$ & Temp. \\
\hline 1 & $150-250 \mu \mathrm{m}$ & $1 \mathrm{~N} \mathrm{HCl}$ (5 mins) & $\mathrm{Dl}^{\mathrm{a}}$ water (3 mins) & $50 \%(\mathrm{v} / \mathrm{v})$ ethanol (1 $\mathrm{min})$ & $\mathrm{N}_{2}$ & $1 \mathrm{~h}$ & $25^{\circ} \mathrm{C}$ \\
\hline 2 & $150-250 \mu \mathrm{m}$ & $12 \mathrm{~N} \mathrm{HCl}$ (5 mins) & DI water (3 mins) & $50 \%(\mathrm{v} / \mathrm{v})$ ethanol (1 $\mathrm{min})$ & $\mathrm{N}_{2}$ & $1 \mathrm{~h}$ & $25^{\circ} \mathrm{C}$ \\
\hline 3 & $150-250 \mu \mathrm{m}$ & $50 \%(\mathrm{v} / \mathrm{v})$ acetic acid (10 mins) & DI water (3 mins) & $50 \%(v / v)$ ethanol (1 $\mathrm{min})$ & $\mathrm{N}_{2}$ & $1 \mathrm{~h}$ & $25^{\circ} \mathrm{C}$ \\
\hline 4 & $150-250 \mu \mathrm{m}$ & $50 \%(\mathrm{v} / \mathrm{v})$ acetic acid (20 mins) & DI water (3 mins) & $50 \%(\mathrm{v} / \mathrm{v})$ ethanol (1 min) & $\mathrm{N}_{2}$ & $1 \mathrm{~h}$ & $25^{\circ} \mathrm{C}$ \\
\hline
\end{tabular}

${ }^{\mathrm{a} D I}$ : Deionized.

\section{Conclusions}

A method for preparing size-segregated arsenopyrite particles, free of surface oxides for dissolution experiments was developed. A summary of the developed method is shown in Table 3. Arsenopyrite particles in the size fraction of 150-250 $\mu \mathrm{m}$ was obtained by sonication of suspensions of crushed particles in $50 \% \mathrm{v} / \mathrm{v}$ ethanol and verified by particle size distribution and SEM analysis. Four methods of cleaning the surface were investigated and the method involving $12 \mathrm{~N} \mathrm{HCl}$ and 50\% ethanol was found to be the most effective. XPS analysis revealed the method succeeded in removing all oxide species of $\mathrm{S}$ and As on the surface, while only $12 \%$ of surface Fe remained oxidized.

\section{Methods}

\section{Particle size distribution}

The effectiveness of sonication in removing fines was analyzed by measuring the average diameter of the particles by laser diffraction at Particle Tech Labs (Illinois, USA). Ten grams of sonicated and dried arsenopyrite were shipped in a $15 \mathrm{~mL}$ centrifuge tube (Corning USA) for analysis. The particle diameter distribution was calculated on a $\%$ volume basis.

\section{XPS}

XPS measurements were carried out using a PHI 5600ci instrument. The XPS instrument employed monochromatic $\mathrm{Al} \mathrm{K \alpha} \mathrm{X}$-rays and the pass energy of the analyzer was $23.5 \mathrm{eV}$. The arsenopyrite powders were attached to the sample holder using double-sided adhesive, electricallyconductive tape. Percentages of elemental oxidation were calculated from the relative areas of component peaks after the overall peak envelope for a given XPS peak was fitted with the component peaks due to oxidized and unoxidized

\section{Table 3 Summary of arsenopyrite preparation method}

\begin{tabular}{ll}
\hline 1 & $\begin{array}{l}\text { Arsenopyrite was crushed in a mortar and pestle. Dry sieved to } \\
\text { obtain } 150-250 \mu \text { m size fraction. }\end{array}$ \\
2 & Sonicated in $50 \%$ ethanol and supernatant decanted (thrice). \\
4 & Dried under $\mathrm{N}_{2}$ at room temperature for 1 hour. \\
& $\begin{array}{l}\text { Rinsed with } 12 \mathrm{~N} \mathrm{HCl} \text { for } 5 \text { minutes, followed by water (3 minutes) } \\
\text { and } 50 \% \text { ethanol ( } 1 \text { minute) }\end{array}$ \\
\hline
\end{tabular}

forms of the element. Elemental concentrations were calculated using sensitivity factors provided by the instrument manufacturer. XPS peak fitting analyses were accomplished using CasaXPS data processing software. Binding energies were referenced to the $C 1$ s peak for adventitious carbon at $284.6 \mathrm{eV}$.

\section{SEM- EDS}

SEM was used for visual confirmation of arsenopyrite particle size and to evaluate surface composition of the particles. Once a suitable method for cleaning was chosen based on XPS data, arsenopyrite was prepared fresh, stored under vacuum, as previously described, and subjected to analysis within 2 hours of cleaning. The SEM was performed using a Philips XL30 FEG scanning microscope equipped with an SE Everhart Thornley detector and an Oxford INCA EDS with full quantitative composition analysis. The operating conditions were, accelerating voltage $10 \mathrm{kV}$, spot size 3 , and a working distance of $10 \mathrm{~mm}$. The SEM-EDS had a detection limit of $1 \%$ by weight.

\section{Competing interests}

The authors declare that they have no competing interests.

\section{Authors' contributions}

HP carried out the mineral preparation and cleaning protocols, as well as SEM analysis. JB conducted XPS measurements and analysis. AK and DD, conceived the study, co-authored the manuscript, and helped with the analysis of the results. All authors read and approved the manuscript.

\section{Acknowledgements}

We thank Drs. J. Alexandra Hakala and Christina Lopano of National Energy Technology Laboratory for their useful comments.

This project was funded in part by the John and Claire Bertucci Fellowship in Engineering, and by the Department of Energy, National Energy Technology Laboratory (NETL), an agency of the United States Government, through a support contract (DE-FE0004000) with URS Energy \& Construction, Inc as part of the NETL's Regional University Alliance (RUA). Neither the United States Government nor any agency thereof, nor any of their employees, nor URS Energy \& Construction, Inc., nor any of their employees, makes any warranty, expressed or implied, or assumes any legal liability or responsibility for the accuracy, completeness, or usefulness of any information, apparatus, product, or process disclosed, or represents that its use would not infringe privately owned rights. Reference herein to any specific commercial product, process, or service by trade name, trademark, manufacturer, or otherwise, does not necessarily constitute or imply its endorsement, recommendation, or favoring by the United States Government or any agency thereof. The views and opinions of authors expressed herein do not necessarily state or reflect those of the United States Government or any agency thereof. 


\section{Author details}

'Department of Civil and Environmental Engineering, Carnegie Mellon University, Pittsburgh, PA 15213, USA. ${ }^{2}$ U.S. Department of Energy, National Energy Technology Laboratory, Pittsburgh, PA 15236, USA.

Received: 14 May 2014 Accepted: 2 October 2014

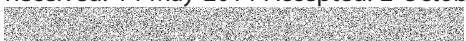

\section{References}

1. Corkhill C, Vaughan D: Arsenopyrite oxidation - a review. App/ Geochem 2009, 12:2342-2361.

2. Walker FP, Schreiber ME, Rimstidt JD: Kinetics of arsenopyrite oxidative dissolution by oxygen. Geochim Cosmochim Acta 2006, 70(7):1668-1676.

3. Mckibben M, Tallant B, Del Angel J: Kinetics of inorganic arsenopyrite oxidation in acidic aqueous solutions. App/ Geochem 2008, 23(2):121-135

4. Yunmei Y, Yongxuan Z, Williams-Jones A, Zhenmin G, Dexian L: A kinetic study of the oxidation of arsenopyrite in acidic solutions: implications for the environment. App/ Geochem 2004, 19(3):435-444.

5. Asta MP, Cama J, Ayora C, Acero P, de Giudici G: Arsenopyrite dissolution rates in $\mathrm{O}_{2}$-bearing solutions. Chem Geol 2010, 273(3-4):272-285.

6. Mckibben MA, Barnes $\mathrm{HL}$ : Oxidation of pyrite in low temperature acidic solutions: rate laws and surface textures. Geochim Cosmochim Acta 1986, 50(7):1509-1520.

7. Yunmei Y, Yongxuan Z, Zhenmin G, Gammons CH, Li D: Rates of arsenopyrite oxidation by Oxygen and $\mathrm{Fe}$ (III) at $\mathrm{pH} 1.8-12.6$ and $15-45^{\circ} \mathrm{C}$. Environ Sci Technol 2007, 41(18):6460-6464.

8. Wolfe AL, Liu R, Stewart BW, Capo RC, Dzombak DA: A method for generating uniform size-segregated pyrite particle fractions. Geochem Trans 2007, 8(1):9.

9. Moses C, Kirk Nordstrom D, Herman J, Mills A: Aqueous pyrite oxidation by dissolved oxygen and by ferric iron. Geochim Cosmochim Acta 1987, 51(6):1561-1571.

10. Buckley AN, Walker GW: The surface composition of arsenopyrite exposed to oxidizing environments. App/ Surf Sci 1998, 35(2):227-240.

11. Nesbitt H, Muir I, Prarr A: Oxidation of arsenopyrite by air and airsaturated, distilled water, and implications for mechanism of oxidation. Geochim Cosmochim Acta 1995, 59(9):1773-1786.

12. Costa $M$, Botelho Do Rego A, Abrantes L: Characterization of a natural and an electro-oxidized arsenopyrite: a study on electrochemical and X-ray photoelectron spectroscopy. Int J Miner Process 2002, 65(2):83-108.

13. Buckley AN, Woods R: The surface oxidation of pyrite. App/ Surf Sci 1987, 27(4):437-452

14. Schaufuss AG, Nesbitt HW, Scaini MJ, Hoechst $H$, Bancroft MG, Szargan R: Reactivity of surface sites on fractured arsenopyrite (FeAsS) toward oxygen. Am Mineralogist 2000, 85(11-12):1754

15. Nesbitt H, Muir I: Oxidation states and speciation of secondary products on pyrite and arsenopyrite reacted with mine wastewaters and air. Mineral Petrol 1998, 62(1-2):123-144.

16. Cooper DC, Morse JW: Extractability of metal sulfide minerals in acidic solutions: application to environmental studies of trace metal contamination within anoxic sediments. Environ Sci Technol 1998, 32(8):1076-1078

\section{doi:10.1186/s12932-014-0014-9}

Cite this article as: Parthasarathy et al:: A method for preparation and cleaning of uniformly sized arsenopyrite particles. Geochemical Transactions 2014 15:14. 